\title{
A Single-Phase Current-Source Bidirectional Converter for V2G Applications
}

\author{
Hua Han ${ }^{*}$, Yonglu Liu*, Yao Sun ${ }^{\dagger}$, Hui Wang ${ }^{*}$, and Mei Su ${ }^{*}$ \\ $\dagger^{\dagger *}$ Department of Information Science and Engineering, Central South University, Changsha, China
}

\begin{abstract}
In this paper, a single-phase current-source bidirectional converter topology for $\mathrm{V} 2 \mathrm{G}$ applications is proposed. The proposed converter consists of a single-phase current-source rectifier (SCSR) and an auxiliary switching network (ASN). It offers bidirectional power flow between the battery and the grid in the buck or boost mode and expands the output voltage range, so that it can be compatible with different voltage levels. The topology structure and operating principles of the proposed converter are analyzed in detail. An indirect control algorithm is used to realize the charging and discharging of the battery. Finally, the semiconductor losses and system efficiency are analyzed. Simulation and experimental results demonstrate the validity and effectiveness of the proposed topology.
\end{abstract}

Key words: Battery charger, Bidirectional converter, Current ripple, V2G

\section{INTRODUCTION}

Developing plug-in hybrid electric vehicles (PHEV) or electric vehicles (EV) is an effective way to solve the increasingly serious energy crisis and global warming issues because of their reduced fuel usage and greenhouse emissions [1], [2]. If the charging device in a PHEV/EV is designed with bidirectional power transfer capability, the power stored in them can be fed back to the grid, which is termed as a "vehicle-to-grid" (V2G) system [3], [4]. This is reported to be best suited for electricity balancing markets due to the ability to provide services like power system regulation [5], [6], load balancing by valley filling [7] and peak shaving [8], [9].

In a V2G system, the battery charger plays a critical role, because the charging time, the quality of the power and the battery life are linked to it [10], [11]. A battery charger with a high power density, low cost, high efficiency, and flexibility, has been the main focus of current research in both industrial and academic communities. Nowadays, a two-stage topology that voltage-source rectifier (VSR) cascades a dc-dc converter is widely applied in EV/PHEV [12]-[14]. This type of charger offers a two-way electrical energy flow and communication. In addition, the quality of the input current is improved by the PWM technique.

Manuscript received Oct. 10, 2013; accepted Feb. 18, 2014

Recommended for publication by Associate Editor Woo-Jin Choi.

${ }^{\dagger}$ Corresponding Author: yaosuncsu@gmail.com

Tel: +86-731-88876070, Fax: +86-731-88876070, Central South Univ.

*Dept. of Information Science \&Eng., Central South University, China
According to the duality between the VSR and the current-source rectifier (CSR), the CSR is suitable for a battery charger. However, there are relatively few studies on their application to the battery area. Actually the conventional CSR used as a charger was reported early [15]-[17]. However, the reversed energy flow is not allowed. Recently more and more studies have been done on current-source converters (CSC) [18]-[25]. As one type of CSC, the AC/DC matrix converter [18], [19] is attractive in V2G applications due to its inherent bi-directional power flow. However, it needs a large number of semiconductor switches. Therefore, an AC/DC matrix converter topology applied as a battery charger with only three switches has been presented [20]. However, the energy stored in the battery cannot be inverted to the power grid. A charger based on the CSR and H-bridge inverter was reported, where the H-bridge inverter works as an inverting link [21]. It supports bidirectional energy flow and has fewer switches when compared with AC/DC matrix converters. However, undesired redundant switches still exits and that may restrict the scope of its application. Therefore, a simplified topology which can perform multiple functions was studied [22]. For reducing the switch power losses and EMI noise, a bidirectional swiss rectifier [23], [24] and a bidirectional 3rd harmonic injection active filter rectifier [25] were proposed. Their common advantage is that the rectifier works as the fundamental frequency. All the CSCs mentioned above are three phase chargers. When a low power charger is required, for example, when charging at home or in an office, a single 
phase charger is usually preferred [10].

Various topologies and schemes based on a diode rectifier or a voltage-source rectifier have been reported for single phase chargers [10], [26]-[28]. However, few studies have focused on single phase current-source chargers. In [29], a novel inductor voltage control method was proposed for a single phase CSC to achieve any input power factor. Other researchers focused on the power decoupling problem in single phase CSCs [30], [31].

Because the CSR is one kind of buck converter, it is not compatible with higher battery voltages. To realize a bidirectional power flow, increase reliability and expand the application range, a single-phase current-source bidirectional converter topology is presented for $\mathrm{V} 2 \mathrm{G}$ applications in this paper. Its front-end is a conventional CSR and its rear-end is an ASN composed of two IGBTs and two diodes. The role of the front-end SCSR is to convert the supply ac voltage into an intermediate dc link voltage and to realize PFC. The ASN is designed to control the direction of the power flow (charging or discharging). In addition, it works in a PWM manner to help in boosting the output voltage, which greatly expands its application range. Compared with the bidirectional buck-boost converter mentioned in [32], the proposed topology has fewer components, a wider output voltage range and better quality in the input current. A single-phase full bridge bidirectional boost converter cascaded by a DC/DC converter is a commonly used topology in V2G applications. However, it needs larger electrolytic capacitors when compared with the proposed topology, which will limit the lifespan of the converter. In addition, it has the possibility of shoot-through faults due to the nature of the voltage-source converter. Therefore, the proposed converter has a higher reliability. This paper's main objective is to present the principles of charging and discharging with buck-boost modes and to verify the feasibility of the proposed topology, modulation scheme and control algorithm.

This paper is organized as follows: Section II introduces the topology, the operation modes and the averaged switching modeling of the proposed converter. Section III presents the modulation scheme and the control algorithm. Section IV analyzes the semiconductor losses. Section V shows simulation and experimental results to validate the capabilities of the proposed converter. Finally, the main points of this paper are summarized in Section VI.

\section{TOPOLOGY AND MODELING}

\section{A. Topology}

The topology of the proposed single-phase current-source bidirectional converter is shown in Fig. 1. It consists of an $L C$ input filter, a conventional SCSR and an ASN. For the reverse voltage blocking capability, each IGBT in the SCSR is connected with a diode in series. Under normal operation switches $S_{1}$ and $S_{3}$ are complementary; the same restriction is

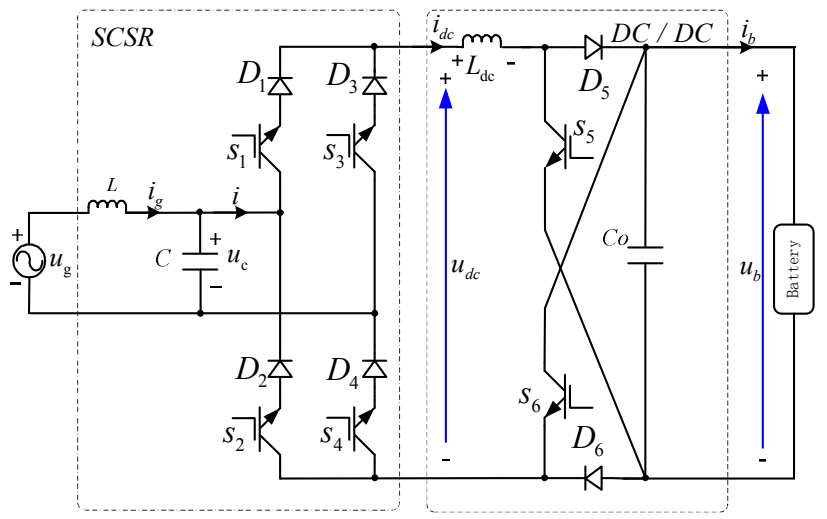

Fig. 1. Topology of the proposed power converter.

applied to $S_{2}$ and $S_{4}$. The ASN includes two IGBTs, two diodes, an inductor $L_{\mathrm{dc}}$ and a capacitor $C_{\mathrm{o}}$, which is the key part of the system. Its main function is to change the direction of the power flow and converter voltage.

\section{B. Operating Modes of the Proposed Topology}

According to the characteristics of the CSR, the dc current $i_{\mathrm{dc}}$ cannot be reversed. However, by controlling the ASN, the direction of the current flowing through the battery can be changed to achieve charging and discharging functionalities. Fig. 2 depicts the four operating modes of the ASN, where the CSR is represented by a controlled voltage source $d_{\mathrm{r}} u_{\mathrm{c}} \cdot d_{r}$ is the difference between the steady state duty ratios of switches $S_{1}$ and $S_{2}$. The red lines illustrate the current paths.

Under the charging operation, $u_{g}$ and $u_{b}$ are the input and output voltages, respectively, and the operating modes alternate between mode I and mode II. In mode I, switches $S_{5}$ and $S_{6}$ are in the off state, diodes $D_{5}$ and $D_{6}$ are forward-biased and the battery absorbs energy. In mode II, switch $S_{5}$ is in the on state and a corresponding diode $D_{6}$ is forward-biased, which disconnects the battery from the circuit. The ASN works as a boost circuit and the system is a buck-boost converter. Therefore, the scope of its application is expanded when compared to the conventional SCSR.

Under the discharging operation, $u_{b}$ and $u_{g}$ are the input and output voltages, respectively, and the operating modes alternate between mode III and mode IV. In mode III, switches $S_{5}$ and $S_{6}$ are in the on state, diodes $D_{5}$ and $D_{6}$ are reverse-biased and the battery supplies energy. Mode IV plays the role of freewheeling. The ASN works as a buck circuit and the system is still a buck-boost converter.

\section{Averaged Switching Model}

By replacing the converter switches with controlled voltage and current sources, the averaged switching model, as shown in Fig. 3, can be derived from Fig.1. According to Fig. 3 , the state space average model for the proposed converter is formulated as follows: 


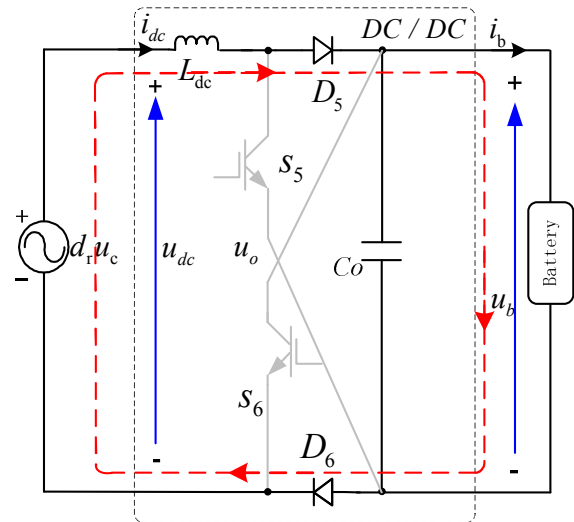

(a)

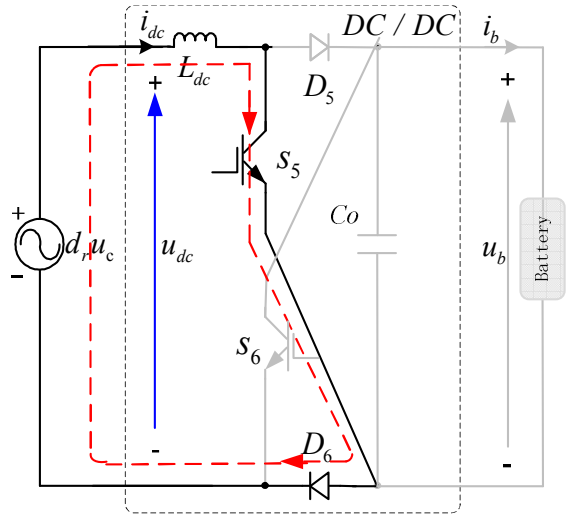

(b)

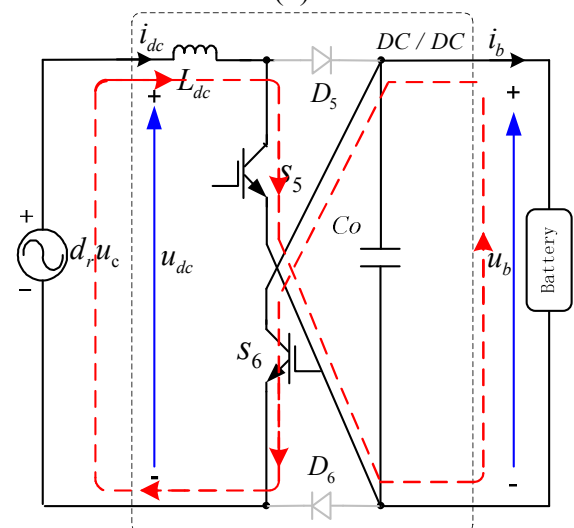

(c)

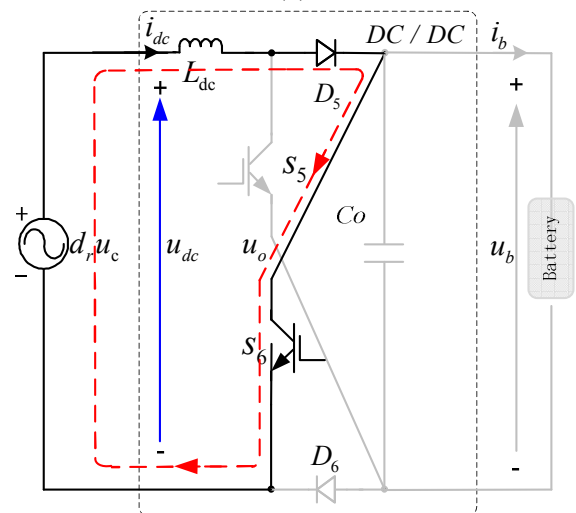

(d)

Fig. 2. Equivalent circuits under different operating modes. (a) mode I. (b) mode II. (c) mode III. (d) mode IV.

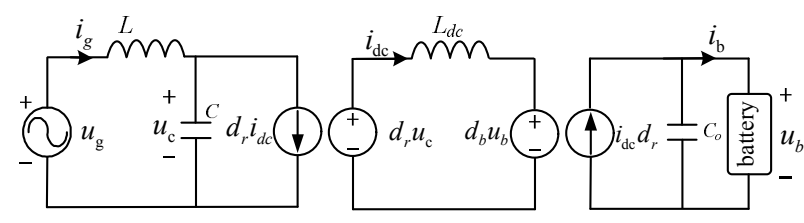

Fig. 3. Averaged switching model.

$$
\begin{gathered}
L \frac{d i_{g}}{d t}=u_{g}-u_{c} \\
C \frac{d u_{c}}{d t}=i_{g}-d_{r} i_{d c} \\
L_{d c} \frac{d i_{d c}}{d t}=d_{r} u_{c}-d_{b} u_{b} \\
C_{o} \frac{d u_{b}}{d t}=d_{b} i_{d c}-i_{b}
\end{gathered}
$$

where, $i_{\mathrm{g}}$ is the gird current, $u_{\mathrm{c}}$ is the terminal voltage of capacitor $C, u_{\mathrm{b}}$ is the battery voltage, $i_{d c}$ is the dc current flowing through inductor $L_{d c}, d_{\mathrm{r}}=d_{1}-d_{2}, d_{\mathrm{b}}=1-d_{5}-d_{6} . d_{\mathrm{i}}$ is the duty ratio of switch $S_{\mathrm{i}}(i \in\{1,2 \ldots 6\})$.

\section{MODULATION AND CONTROL}

\section{A. Modulation Scheme}

Assume that $u_{g}=U \sin (\omega \mathrm{t})$, and that $U$ and $\omega$ represent the grid voltage magnitude and the angle frequency, respectively. In order to obtain a sine grid current with a unity power factor, according to (2), the following equation should be satisfied in the steady state:

$$
i_{\mathrm{g}} \approx d_{r} i_{d c}=I \sin (\omega t)
$$

where, $I$ is the amplitude of the input current. If $I$ is greater than zero, the system works in the charging status; else the system works in the discharging status.

For satisfying the volt-second balance of the inductor $L_{\mathrm{dc}}$, according to equation (3), equation (6) can be obtained (ignoring the effect of the input filter) as follows:

$$
d_{r} u_{g} \approx d_{r} u_{\mathrm{c}}=d_{b} u_{b}
$$

where, $-1 \leq d_{\mathrm{r}}, d_{\mathrm{b}} \leq 1$. It is clear that the value of the battery voltage can be larger or smaller than that of the grid voltage. As a result, the charging/discharging operation under buck/boost mode can be realized.

According to (5) and (6), there is one degree of freedom available. Therefore there are lots of methods to accomplish the control task mentioned above in theory. In this context, $i_{\mathrm{dc}}$ is controlled to be a constant and $d_{\mathrm{r}}$ is controlled to vary with a sine shape, as shown in (7).

$$
\left\{\begin{array}{l}
d_{r}=\mathrm{c} \cdot \operatorname{sgn}(I) \cdot \sin (\omega t) \cdot\left(i_{d c}^{*} / i_{d c}\right) \\
i_{d c}=\text { constant } \\
0 \leq c \leq 1
\end{array}\right.
$$

where $c$ is the modulation index, and $\operatorname{sgn}()$ is the sign function. $i_{d c}^{*}$ is the reference dc current. $\left(i_{d c}^{*} / i_{d c}\right)$ is an extra 
TABLE I

Duty Ratio of EACH Switch UNDER Charging/Discharging OPERATION

\begin{tabular}{c|c|c|c|c|c|c|c}
\hline \hline \multicolumn{2}{c|}{ Working Mode } & $d_{1}$ & $d_{2}$ & $d_{3}$ & $d_{4}$ & $d_{5}$ & $d_{6}$ \\
\hline \multirow{3}{*}{ Charge } & $u_{\mathrm{g}}>0$ & 1 & $1-d_{\mathrm{r}}$ & 0 & $d_{\mathrm{r}}$ & $1-d_{\mathrm{b}}$ & 0 \\
\cline { 2 - 8 } & $u_{\mathrm{g}}<0$ & $1+d_{\mathrm{r}}$ & 1 & $-d_{\mathrm{r}}$ & 0 & $1-d_{\mathrm{b}}$ & 0 \\
\hline \multirow{3}{*}{ Discharge } & $u_{\mathrm{g}}>0$ & $1+d_{\mathrm{r}}$ & 1 & $-d_{\mathrm{r}}$ & 0 & $-d_{\mathrm{b}}$ & 1 \\
\cline { 2 - 8 } & $u_{\mathrm{g}}<0$ & 1 & $1-d_{\mathrm{r}}$ & 0 & $d_{\mathrm{r}}$ & $-d_{\mathrm{b}}$ & 1 \\
\hline \hline
\end{tabular}

compensation term to improve the dynamic responses of the duty cycle to prevent distortion of the grid current. In particular, when the grid voltage $u_{g}$ is near the zero-crossings under the charging operation, the power losses of the circuit and switches are more than the grid can supply. As a result, the current cannot be maintained as a constant and the energy stored in the inductor will be released. Finally, the dc current drop occurs. It should be noted that the duty ratio $d_{\mathrm{r}}$ cannot saturate and the current $i_{d c}$ cannot drop to zero, or distortion will occur. Therefore, the value of the inductor $L_{\mathrm{dc}}$ should be large enough. In the discharging operation, the power losses are always provided by the battery and the current drop will not occur.

From (5) and (7), $I, c$ and $i_{d c}$ satisfy the restriction $|I|=c \cdot i_{d c}$. Taking the power losses into account, a minimal $i_{d c}$ is expected. Therefore, according to (6) and (7), $c$ can be given by:

$$
c=\min \left(\frac{u_{b}}{U}, 1\right)
$$

where, $\min ()$ is the minimum function.

According to (6), $d_{b}$ can be obtained as follows:

$$
d_{b}=\mathrm{c} U \sin ^{2}(\omega t) i_{d c}^{*} /\left(i_{d c} u_{b}\right)
$$

In this paper, for minimizing the power losses the combination of switches is restrained further as follows: if $d_{\mathrm{r}}>0, d_{1}=1$; otherwise, $d_{2}=1$. If $I>0, d_{6}=0$; otherwise, $d_{6}=1$. Therefore, the duty ratio of each switch can be determined as shown in Table I.

\section{B. Control Algorithm}

A control diagram for realizing the charging/discharging is shown in Fig. 4. To improve the reliability and reduce the cost, only the grid voltage, the battery terminal voltage and the current through the inductance $L_{d c}$ are sampled. To regulate the current through the inductor, a control scheme including feed-forward control and PI feedback control is presented. The feed-forward control compensates the effects of the grid voltage directly, which increases the dynamic response of the current control. The PI control will help to stabilizing the system and handle some unknown disturbance. A simple open-loop control is used for modifying $d_{\mathrm{r}}$ to obtain a sine grid current and to realize PFC.

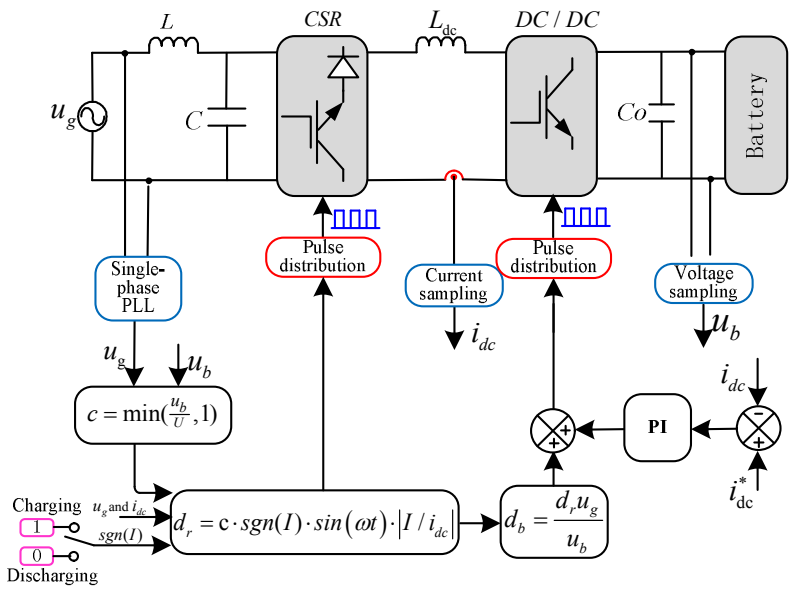

Fig. 4. Control diagram of charging, and discharging.

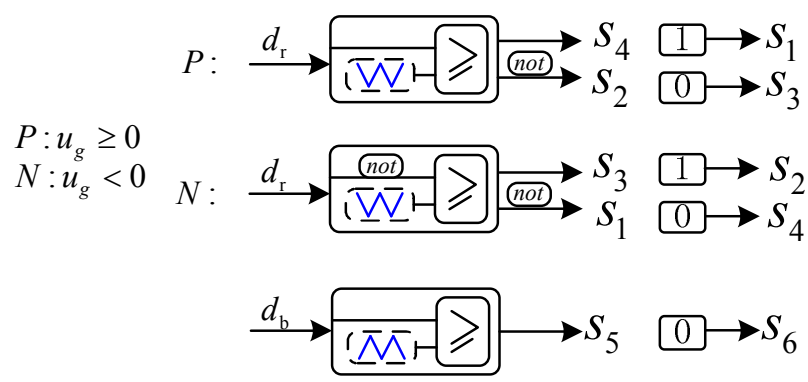

(a)

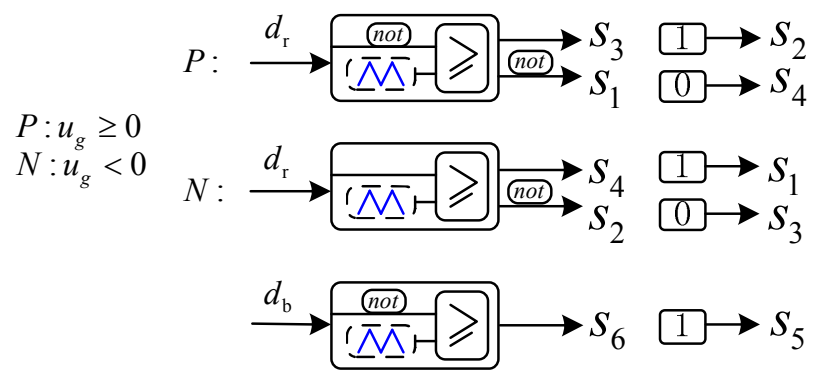

(b)

Fig. 5. Operations of switches under different modes. (a) Under charging operation. (b) Under discharging operation.

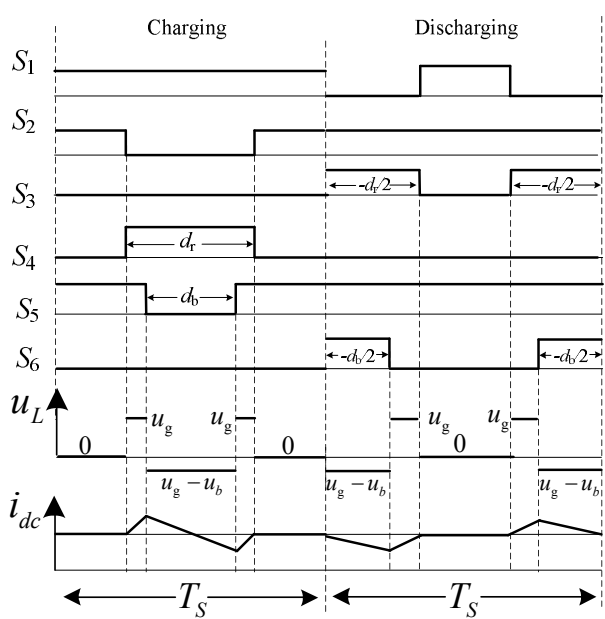

Fig. 6. Switching pattern arrangements under different modes $\left(u_{\mathrm{g}}>0, u_{\mathrm{g}}<u_{\mathrm{b}}\right)$. 


\section{Switching Pattern Arrangements}

The performance of the converter depends on both the modulation strategy and the switching pattern arrangement. In this paper, reducing the switching power losses and output current ripple are the main consideration when arranging the switching pattern. Therefore, a symmetrical switching pattern is usually applied [20]. Both the front-end switching pattern and the rear-end switching pattern need to be arranged. In addition, coordination control between the front-end switching pattern and the rear-end switching pattern is required.

In this paper, the in-phase carrier PWM modulator is adapted under the charging operation, and the interleaved carrier PWM modulator is adapted under the discharging operation. Fig. 5 illustrates the specific operation of each switch in each switching period. An example is given in Fig.6 to show the changes of the voltage across inductor $L$ and the dc current $i_{d c}$. Here the voltage drops across the IGBTs and the diodes are neglected. From Fig. 6 the switching patterns are bilaterally symmetrical, and twice commutations occur in each switching period.

\section{LOSSES ANALYSIS}

The power losses calculation of a power converter is crucial since it influences the design of the cooling system of power electronic equipment and is associated with the efficiency of the converter [33]. Usually, the power losses during the off-state can be neglected since they are considerably low when compared to the amount of the total conduction losses and switching losses. Therefore, the two main kinds of power semiconductor losses are considered here: conduction losses and switching losses. According to [33], [34], the computational formulas for the conduction losses and switching losses are expressed as:

$$
\begin{gathered}
P_{c_{-} S}=\frac{1}{T} \int_{0}^{T}\left(V_{C E 0} i_{T_{-} a v g}+r_{C E} i_{T_{-} r m s}^{2}\right) d t \\
P_{c_{-} D}=\frac{1}{T} \int_{0}^{T}\left(V_{F 0} i_{D_{-} a v g}+r_{F} i_{D_{-} r m s}^{2}\right) d t \\
P_{s w}=f_{s} \cdot \frac{1}{T} \int_{0}^{T} E_{S W R} \frac{v}{V_{R}} \frac{i}{I_{R}} d t
\end{gathered}
$$

where $P_{c-S}$ is the conduction loss of the IGBT, $P_{c-D}$ is the conduction loss of the diode, $P_{s w}$ is the switching loss of the IGBT or diode, $T$ is the period of the integrated function, $f_{\mathrm{S}}$ is the switching frequency, $V_{C E O}$ and $V_{F O}$ are the forward voltages when the current is zero, $r_{C E}$ and $r_{F}$ are the incremental resistances of the IGBT and the diode, $i_{T_{-} \text {avg }}$ and $i_{D \_a v g}$ are the average of the currents flowing through the IGBT and diode, $i_{T_{-} r m s}$ and $i_{D_{-} r m s}$ are the RMS of the current flowing through the IGBT and diode, $E_{S W R}$ is the switching energy at the loss reference conditions $\left(V_{R}\right.$ and $\left.I_{R}\right)$. For the IGBT, $E_{S W R}$ represents the turn-on energy $E_{\text {on_ } T}$ and the turn-off energy $E_{\text {off- }}$; for the diode, $E_{S W R}$ is typically caused by the reverse recovery losses $E_{r r_{-} D}$.
TABLE II

LOSSES ANALYSIS WHEN $u_{g}$ IS POSITIVE UNDER CHARGING OPERATION

\begin{tabular}{ccccccc}
\hline \hline IGBT/diode & $\mathrm{S}_{1}$ & $\mathrm{D}_{1}$ & $\mathrm{~S}_{2}$ & $\mathrm{D}_{2}$ & $\mathrm{~S}_{3}$ & $\mathrm{D}_{3}$ \\
\hline losses & 1 & (1) & (1) & (1) 3 & & \\
\hline \hline IGBT/diode & $\mathrm{S}_{4}$ & $\mathrm{D}_{4}$ & $\mathrm{~S}_{5}$ & $\mathrm{D}_{5}$ & $\mathrm{~S}_{6}$ & $\mathrm{D}_{6}$ \\
\hline losses & (1)(2)(3) & (1) & (1)(2) 3 & (1) 3 & & 1 \\
\hline \hline
\end{tabular}

(1), Conduction losses; (2), Turn-on losses; (3), Turn-off losses

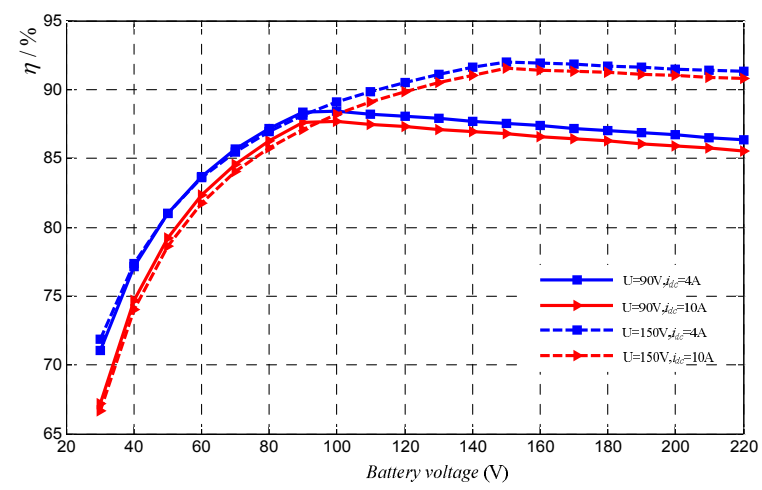

Fig. 7. Efficiency variation with the battery voltage.

According to the previously mentioned modulation scheme, it can be seen that the charging operation and discharging operation have the same switching losses and only the conduction losses are slightly different. To avoid repetition, only the losses under the charging operation are calculated. Due to symmetry, only the losses during the positive half cycle are taken into account and the results of the loss analysis are summarized in Table II . Note that the reverse voltage across diode $D_{4}$ is negative in the turn-off process. As a result, there is no turn-off loss happening to $D_{4}$. A similar analysis can be applied to $S_{2}$.

The total conduction losses $P_{c f \text { front }}$ and the total switching losses $P_{\text {sw front }}$ of the front-end SCSR can be expressed as:

$$
\begin{aligned}
P_{c_{-} \text {front }}= & P_{c_{-} S_{1}}+P_{c_{-} S_{2}}+P_{c_{-} S_{4}}+P_{c_{-} D_{1}}+P_{c_{-} D_{2}}+P_{c_{-} D_{4}} \\
= & 2\left(V_{F 0}+V_{C E 0}\right) i_{d c}+2\left(r_{F}+r_{C E}\right) i_{d c}^{2} \\
P_{s w_{-} \text {front }} & =P_{s w_{-} S_{4}}+P_{s w_{-} D_{2}} \\
= & \frac{2}{\pi} \frac{f_{s} U i_{d c}}{V_{R} I_{R}}\left(E_{\text {on } T}+E_{o f f_{-} T}+E_{r r_{-} D}\right)
\end{aligned}
$$

The total conduction losses $P_{c_{-} \text {rear }}$ and the total switching losses $P_{s w_{-} \text {rear }}$ of the rear-end ASN can be expressed as:

$$
\begin{aligned}
& P_{c_{-} \text {rear }}=P_{c_{-} S_{5}}+P_{c_{-} D_{5}}+P_{c_{-} D_{6}} \\
& =\frac{i_{d c}}{2 u_{b}}\left(2 u_{b}\left(V_{C E 0}+V_{F 0}\right)+c U\left(V_{F 0}-V_{C E 0}\right)\right)+ \\
& \frac{i_{d c}^{2}}{2 u_{b}}\left(2 u_{b}\left(r_{C E}+r_{F}\right)+c U\left(r_{F}-r_{C E}\right)\right) \\
& P_{s w_{-} r e a r}=P_{s w_{-} S_{5}}+P_{s w_{-} D_{5}} \\
& =\frac{f_{s} u_{b} i_{d c}}{V_{R} I_{R}}\left(E_{\text {on_ } T}+E_{\text {off }-T}+E_{r r_{-} D}\right)
\end{aligned}
$$

The total losses are given by: 
TABLE III

PARAMETERS USED FOR SIMULATION

\begin{tabular}{lc}
\hline \multicolumn{1}{c}{ parameters } & value \\
\hline Amplitude of input phase voltage $U$ & $92 \mathrm{~V}$ \\
Input filter inductor $L$ & $0.6 \mathrm{mH}$ \\
Input filter capacitor $C$ & $10 \mathrm{uF}$ \\
Output filter inductor $L_{d c}$ & $1.6 \mathrm{mH}$ \\
Output filter capacitor $C_{0}$ & $20 \mu \mathrm{F}$ \\
The reference current $i_{d c}^{*}$ & $4 \mathrm{~A}$ \\
Switching frequency $f_{s}$ & $20 \mathrm{kHz}$ \\
Value of the battery voltage $u_{b}$ & $60 \mathrm{~V} / 120 \mathrm{~V}$ \\
\hline
\end{tabular}

$$
P_{\text {total }}=P_{c_{-} \text {front }}+P_{s w_{-} \text {front }}+P_{c_{-} \text {rear }}+P_{s w_{-} \text {rear }} .
$$

According to the foregoing calculation results, the larger the dc current $i_{\mathrm{dc}}$ is, the greater the semiconductor losses become. Fig. 7 shows the efficiency variation as a function of the battery voltage when the grid voltage is $90 \mathrm{~V} / 150 \mathrm{~V}$ and the dc current $i_{d c}$ is $4 \mathrm{~A} / 10 \mathrm{~A}$. As can be seen, the efficiency at $U=150 \mathrm{~V}$ is higher than the efficiency at $U=90 \mathrm{~V}$ under the same battery voltage conditions. Their maximum efficiency is larger than $87 \%$ and $92 \%$ relatively, and it is more effective when the grid voltage is near the battery voltage. When $i_{\mathrm{dc}}$ is $4 \mathrm{~A}$, the amplitude of the grid voltage is $90 \mathrm{~V}$ and the battery voltages are $60 \mathrm{~V}$ and $120 \mathrm{~V}$. According to the power analyzer, the measured efficiencies of the converter are $77 \%$ and $83 \%$. From Fig.7, it can be seen that the measured efficiencies are slightly smaller than the theoretical efficiencies $(83.32 \%$ for $u_{\mathrm{b}}=60 \mathrm{~V}, 87.47 \%$ for $u_{\mathrm{b}}=120 \mathrm{~V}$ ) since the losses caused by the passive components are taken into consideration in the experiments.

\section{SIMULATION AND EXPERIMENTAL RESULTS}

\section{A. Simulation}

To validate the proposed topology and method, simulations based on the Matlab/Simulink environment are implemented in this section. The models of the semiconductor devices and battery are from the SimPowerSystems/Power Electronics library. A schematic diagram of the single-phase currentsource bidirectional converter in the simulation is shown in Fig. 1. The parameters used in the simulation are listed in Table III. The loads are 40Ah capacity lead-acid batteries with two different nominal voltages: $60 \mathrm{~V}$ and $120 \mathrm{~V}$, respectively.

The simulation results in Fig. 8 show the performance of the proposed converter. From the top, the grid voltage $u_{g}$, the grid current $i_{\mathrm{g}}$, the output voltage $u_{\mathrm{dc}}$, the dc current $i_{\mathrm{dc}}$, the battery voltage $u_{\mathrm{b}}$ and the battery current $i_{\mathrm{b}}$ are sequentially displayed. The simulation starts with the charging operation and is changed to the discharging operation at $0.03 \mathrm{~s}$. It can be clearly seen that in the charging mode, the grid currents are in

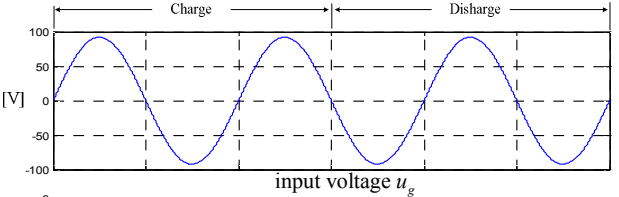

[A]
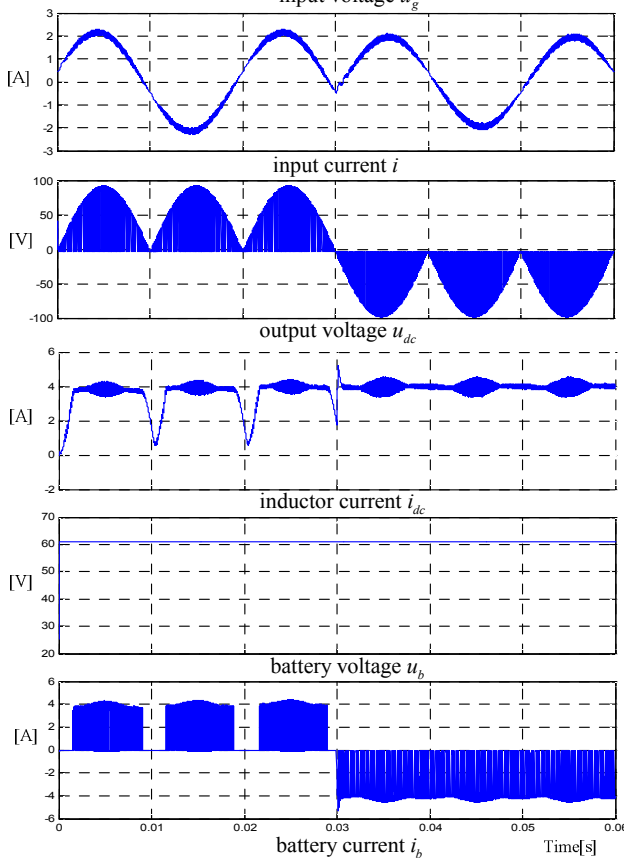

(a)
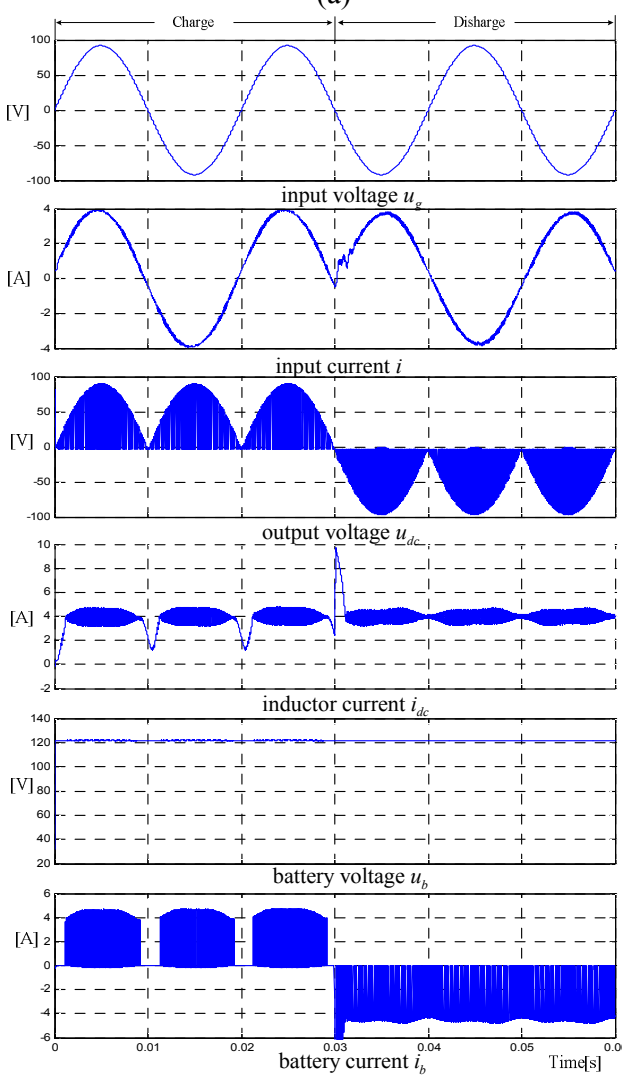

(b)

Fig. 8. Simulation results of charging/discharging when reference current is 4 Amps. (a) The battery voltage is $60 \mathrm{~V}$. (b) The battery voltage is $120 \mathrm{~V}$. 


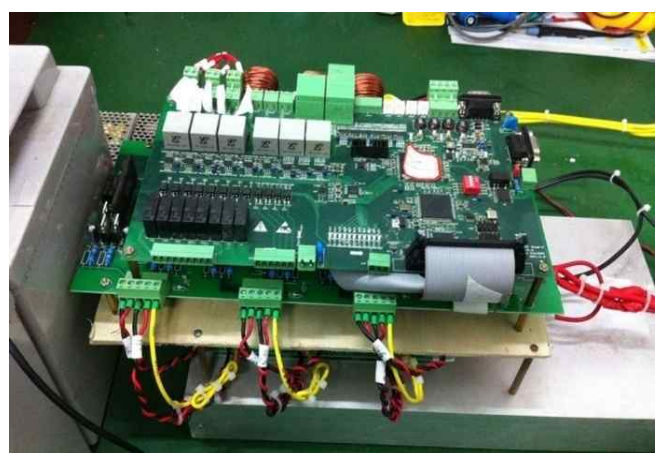

Fig. 9. Prototype of the single-phase current-source bidirectional converter built in the laboratory.

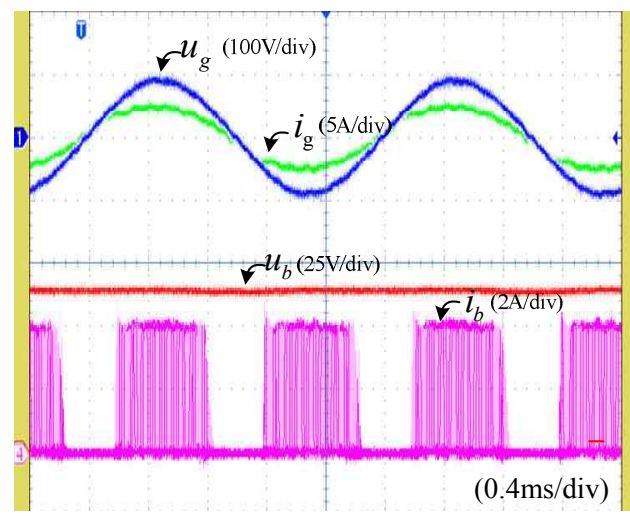

(a)

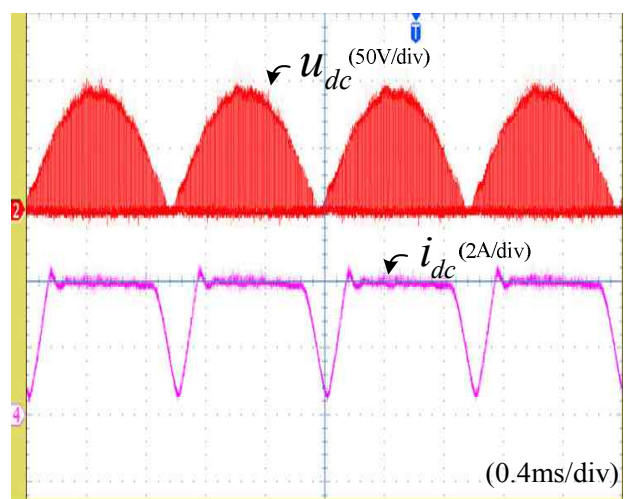

(b)

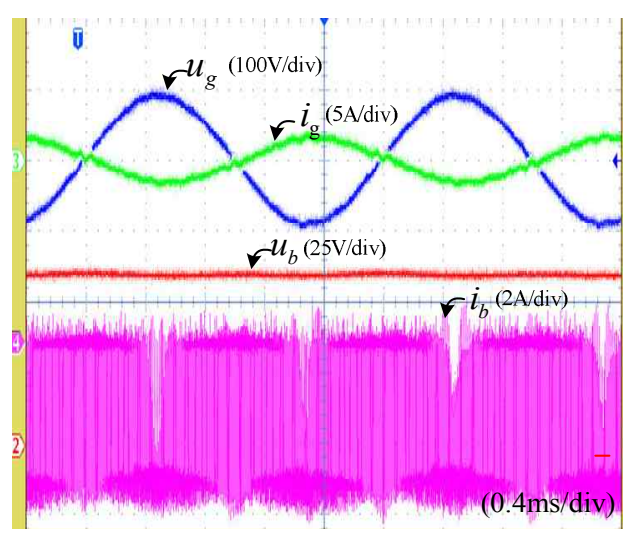

(c)

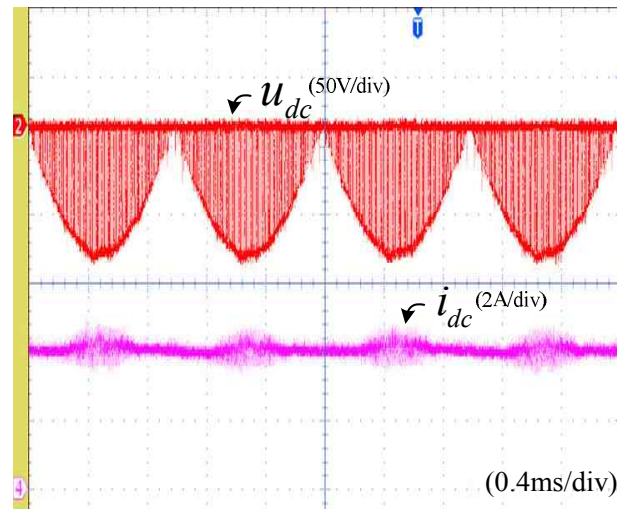

(d)

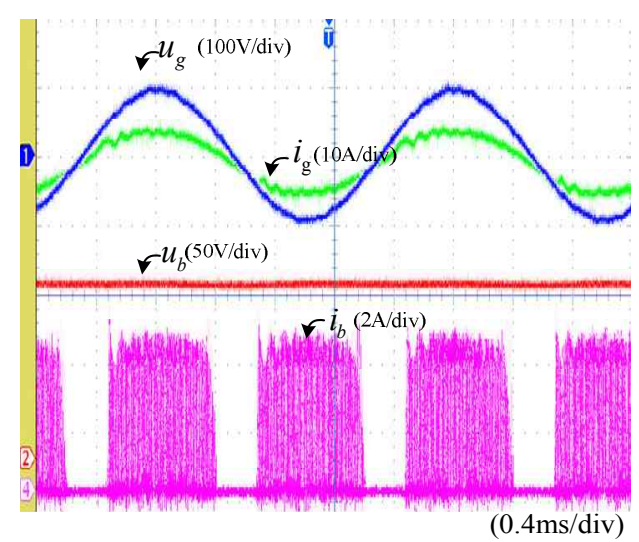

(e)

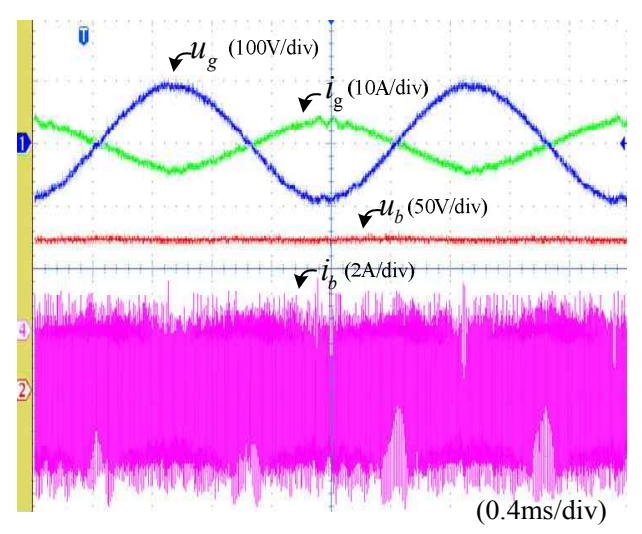

(f)

Fig. 10. Experimental results. (a) Grid voltage, grid current, battery voltage and charging current in charging mode when battery voltage is $60 \mathrm{~V}$. (b) Output voltage and dc current in charging mode when battery voltage is $60 \mathrm{~V}$. (c) Grid voltage, grid current, battery voltage and charging current in discharging mode when battery voltage is $60 \mathrm{~V}$. (d) Output voltage and dc current in charging mode when battery voltage is $60 \mathrm{~V}$. (e) Grid voltage, grid current, battery voltage and charging current in charging mode when battery voltage is $120 \mathrm{~V}$. (f) Grid voltage, grid current, battery voltage and charging current in discharging mode when battery voltage is $120 \mathrm{~V}$. 
phase with the grid voltages, while in the discharging mode, the input currents and the grid voltages are out of phase by $180^{\circ}$. An interesting phenomenon can be found in the fact that the inductor current is distorted near the grid voltage zero-crossing region in all of the charging modes, even though it is designed to be controlled as a constant value. The reason is that the forward voltage drop of the IGBTs and diodes makes the inductor current lose control when the input voltage is smaller than the sum of the voltage drops due to the semiconductor devices in the proposed converter. Though the inductor current is distorted, it does not affect the input current due to the real-time compensation of $d_{\mathrm{r}}$. In addition, in the discharging mode, as the battery is a constant voltage source, it can overcome the forward voltage and keep the inductor current constant. As a result, the inductor current is controlled well without distortion. In conclusion, the input current is in phase with the input voltage, and it is close to a unity power factor, and the input current is sinusoidal in all of the modes.

\section{B. Experiments}

A prototype for the proposed converter is built in the lab for experimental verification, as shown in Fig. 9. The parameter settings are the same as those in the simulation. The IGBTs used in the main circuit are 1MBH60D-100, and the fast recovery diodes are DSEI30-12A. The microprocessor of the converter was realized by a combination of a TMS320F28335 digital signal processor and a field programmable gate array EP2C8T144C8N FPGA. Two groups of lead-acid battery packs are used in this experiment, and their specifications are $60 \mathrm{~V} / 20 \mathrm{Ah}$ and $120 \mathrm{~V} / 20 \mathrm{Ah}$, respectively.

The experimental results presented in Fig.10 show the performance of the single-phase current-source bidirectional converter operating with battery voltages of $60 \mathrm{~V}$ and $120 \mathrm{~V}$. The reference output current is always set to $4 \mathrm{~A}$.

Fig. 10(a) illustrates the grid voltage, the grid current, the battery voltage and the charging current in the charging mode when a lead-acid battery pack of $60 \mathrm{~V} / 20 \mathrm{Ah}$ is connected to the converter. It can be found that the grid current is sinusoidal and in phase with the grid voltage. Fig. 10(b) and Fig. 10(d) show the measured waveforms of the output voltage and $\mathrm{dc}$ current in the charging mode and the discharging mode, respectively. As can be seen, in addition to being near the zero-crossings of the grid voltage when charging, the dc current tracks its reference well with a small ripple. This indicates that the switching patterns used in this paper work well. As can be seen from Fig. 10(a) and Fig. 10(b), due to the fact that the compensation though the dc current drop occurs, the distortion does not occur to the grid current. To feed energy back to the grid, the converter should operate in the discharging mode, and the experimental results are illustrated in Fig. 10(c). Since the battery provides energy back to the grid, the grid current is sinusoidal and in phase opposition to the grid voltage.

To verify that the proposed topology has a large output voltage range, a lead-acid battery pack of $120 \mathrm{~V} / 20 \mathrm{Ah}$ is connected to the converter. Fig. 10(e) and Fig. 10(f) show the experimental waveforms. As can be seen, the experimental results are in good agreement with the simulation results. It can be concluded that the high quality of the input current and high performance of the charging and discharging are easily obtained under the charging/discharging operation.

\section{CONCLUSIONS}

This study presents a single-phase current-source bidirectional converter topology which is suitable for an interface in a V2G system. The proposed converter can work in buck-boost charging/discharging operation, and offers different voltage levels that are appropriate for charging/discharging the batteries. In this paper, the output current is controlled as a constant. The feed-forward control is necessary to ensure the grid current quality. The coordinated control of the front-end switching pattern and rear-end switching pattern is used to reduce the current ripple. The semiconductor losses are also analyzed in detail. In conclusion, the proposed converter has a number of attractive features, such as a simplified topology, a bidirectional power flow, reliability and a wide output voltage range, and it is a good candidate for $\mathrm{V} 2 \mathrm{G}$ applications.

\section{ACKNOWLEDGMENT}

This work was supported by the Hunan Provincial Natural Science Foundation of China under Grant 14JJ5035 and the National High-tech R\&D Program of China (863 Program) under Grant 2012AA051603 and 2012AA051604.

\section{REFERENCES}

[1] M. Kinter-Meyer, K. Schneider, and R. Pratt, "Impacts assessment of plug-in hybrid electric vehicles on electric utilities and regional U.S. power grids - Part IV technical analysis," Pacific North West National Lab., Richland, WA, PNNL-SA-61669, Jan. 2007.

[2] J. A. P. Lopes, F. J. Soares, and P. M. R. Almeida, "Integration of electric vehicles in the electric power system," in Proc. IEEE, Vol. 99, No. 1, pp. 168-183, Jan. 2011.

[3] W. Kempton and J. Tomic, "Vehicle-to-grid power fundamentals: Calculating capacity and net revenue," $J$. Power Sources, Vol. 144, No. 1, pp. 268-279, Jun. 2005.

[4] V. V. Viswanathan and M. Kintner-Meyer, "Second use of transportation batteries: Maximizing the value of batteries for transportation and grid services," IEEE Trans. Veh. Technol., Vol. 60, No. 7, pp. 2963-2970, Sep. 2011.

[5] W. Kempton and J. Tomic, "Vehicle-to-grid power implementation: From stabilizing the grid to supporting 
large-scale renewable energy," J. Power Sources, Vol. 144, No. 1, pp. $280-294$, Jun. 2005

[6] J. Tomic and W. Kempton, "Using fleets of electric-drive vehicles for grid support," J. Power Sources, Vol. 168, No. 2, pp. 459 -468, Jun. 2007

[7] F. Koyanagi and Y. Uriu, "A strategy of load leveling by charging and discharging time control of electric vehicles," IEEE Trans. Power Syst. ,Vol. 13, No. 3, pp. 1179-1184, Aug. 1998.

[8] E. Sortomme and M. A. El-Sharkawi, "Optimal scheduling of vehicle-to-grid energy and ancillary services," IEEE Trans. Smart Grid, Vol.3, No. 1, pp. 351-359, Mar. 2012.

[9] M. Yilmaz and P. T. Krein, "Review of the Impact of Vehicle-to-Grid Technologies on Distribution Systems and Utility Interfaces," IEEE Trans. Power Electron., Vol.28, No.12, pp. 5673-5689, Dec. 2013.

[10] M. Yilmaz and P. T. Krein, "Review of battery charger topologies, charging power levels, and infrastructure for plug-in electric and hybrid vehicles," IEEE Trans. Power. Electron., Vol. 28, No. 5, pp.2151-2169, May 2013.

[11] J. Gallardo-Lozano, M. Isabel Milanés-Montero, M. A. Guerrero-Martínez, and E.Romero-Cadaval. "Electric vehicle battery charger for smart grids," Elect. Power Syst. Res., Vol. 90, pp.18 -29, Sep. 2012.

[12] D. C. Erb , O. C. Onar, and A. Khaligh, "Bi-directional charging topologies for plug-in hybrid electric vehicles," in Proc. IEEE Appl. Power Electron. Conf. Expo., pp. 2066 $-2072,2010$.

[13] S. Haghbin , S. Lundmark, M. Alakula, and O. Carlson, "Grid-connected integrated battery chargers in vehicle applications: Review and new solution," IEEE Trans. Ind. Electron., Vol. 60, No. 2, pp.459 -473, Feb. 2013.

[14] A. Khaligh and S. Dusmez, "Comprehensive topological analysis of conductive and inductive charging solutions for plug-in electric vehicles," IEEE Trans. Veh. Technol., Vol. 61, No. 8, pp.3475-3489, Oct. 2012.

[15] D. Graovac and V. Katie, "Online control of current-source-type active rectifier using transfer function approach," IEEE Trans. Ind. Electron., Vol. 48, No. 3, pp. 526-535, Jun. 2001.

[16] T. C. Green, M. H. Taha, N. A. Rahim, and B. W. Williams, "Three-phase Step-down Reversible AC-DC Power Converter," IEEE Trans. Power Electron., Vol. 12, No. 2, pp. 319-324, Mar. 1997.

[17] K.-Y. Kim, S.-H. Park, S.-K. Lee, T.-K. Lee, and C.-Y. Won, "Battery charging system for PHEV and EV using single phase AC/DC PWM buck converter," in Vehicle Power and Propulsion Conference (VPPC), IEEE, pp. 1-6, 2010.

[18] D. G. Holmes and T. A Lipo, "Implementation of a controlled rectifier using ac-ac matrix converter theory," IEEE Trans. Power Electron., Vol. 7, No. 1, pp.240 -250, Jan. 1992.

[19] M. Su, H. Wang, Y. Sun, J. Yang, W. Xiong, and Y. Liu, "AC/DC Matrix Converter with an optimized modulation strategy for V2G Applications," IEEE Trans. Power Electron., Vol. 28, No. 12, pp.5736-5745, Dec. 2013.

[20] R. Metidji, B. Metidji, and B. Mendil, "Design and implementation of unity power factor fuzzy battery charger using ultra sparse matrix rectifier," IEEE Trans. Power Electron. Vol. 28, No. 5, pp. 2269-2276, May 2013.

[21] K. Wei, Z. Lixia, W. Yansong, L. Huber, and D. Borojevic, "Study on output characteristic of bi-direction current source converters," IET Power Electron., Vol. 5, No. 7, pp. 929-934, Aug. 2012.
[22] Y. Sun, W. Liu, M. Su, X. Li, H. Wang, and J. Yang, "A unified modeling and control of a multi-functional current source-typed converter for V2G application," Electric Power Systems Research, Vol. 106, pp. 12-20, Jan. 2014.

[23] T. Soeiro, T. Friedli, and J. W. Kolar, "Swiss rectifier-a novel threephase buck-type PFC topology for electric vehicle battery charging," in Proc. 27th Annu. IEEE Appl. Power Electron. Conf. Expo., pp. 2617-2624, Feb. 2012.

[24] M. F. Vancu, T. Soeiro, J. Muhlethaler, J. W. Kolar, and D. Aggeler, "Comparative evaluation of bidirectional buck-type PFC converter systems for interfacing residential DC distribution systems to the smart grid," IECON 2012-38th Annual Conference on IEEE Industrial Electronics Society. pp. 5153-5160, 2012.

[25] B. Soeiro, F. Vancu, and J. W. Kolar, "Hybrid active third-harmonic current injection mains interface concept for DC distribution systems," IEEE Trans. Power Electron., Vol. 28, No. 1, pp. 7-13, Jan. 2013.

[26] B. Singh, B. N. Singh, A. Chandra, K. Al-Haddad, A. Pandey, and D. P. Kothari, "A review of single-phase improved power quality AC-DC converters," IEEE Trans. Ind. Electron., Vol. 50, No. 5, pp. 962-981,Oct. 2003.

[27] Y. Du, S. M. Lukic, B. S. Jacobson, and A. Q. Huang, "Review of high power isolated bi-directional DC-DC converters for PHEV/EV DC charging infrastructure," in IEEE 2011 Energy Conversion Congress and Exposition (ECCE), pp. 553-560, 17-22, Sep. 2011.

[28] S. Dusmez and A. Khaligh, "A compact and integrated multifunctional power electronic interface for plug-in electric vehicles," IEEE Trans. Power Electron., Vol. 28, No. 12, pp. 5690-5701, Dec. 2013.

[29] R. Oruganti and M. Palaniapan, "Inductor voltage control of buck-type single-phase AC-DC converter," IEEE Trans. Power Electron., Vol. 15, pp. 411-417, Mar. 2000.

[30] F. F. Zapata, L. D. Salazar, and J. R. Espinoza, "Analysis and design of a single-phase PWM current source rectifier with neutral leg," in Proc. IEEE IECON'98, pp. 519-524, 1998.

[31] S. Z. Dai, N. Lujara, and B. T. Ooi, "A unity power factor current regulated SPWM rectifier with a notch feedback for stabilization and active filtering," IEEE Trans. Power Electron., Vol. 7, No. 2, pp. 356-363, Apr. 1992.

[32] K. M. Bogdan and T. Citko, "Application of the AC link in power conversion systems," in Proc. EPE'97, pp. 4459-4464, 1997.

[33] M. H. Bierhoff and F. W. Fuchs, "Semiconductor losses in voltage source and current source IGBT converters based on analytical derivation," in Proc. IEEE 35th Power Electronics Specialists Conf. (PESC), Vol. 4, pp.2836-2842, 2004.

[34] B. Wang and G. Venkataramanan, "Analytical modeling of semiconductor losses in matrix converters," in Power Electronics and Motion Control Conference, 2006. IPEMC 2006. CES/IEEE 5th International, Vol. 1, pp. 1-8, Aug, 2006.

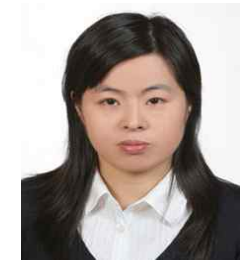

Hua Han was born in Hunan, China, in 1970 She received her M.S. and Ph.D. degrees from the School of Information Science and Engineering, Central South University, Changsha, China, in 1998 and 2008, respectively. She was a Visiting Scholar at the University of Central Florida, Orlando, 
FL, USA, from April 2011 to April 2012. She is presently an Associate Professor with the School of Information Science and Engineering, Central South University. Her current research interests include micro-grids, renewable energy power generation systems and power electronic equipment.

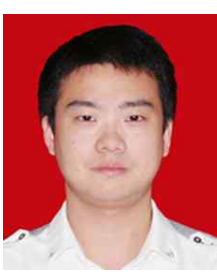

Yonglu Liu was born in Chongqing, China, in 1989. He received his B.S. degree in Electronic Engineering from the Central South University, Changsha, China, in 2012, where he is presently pursuing his M.S. degree in Electrical Engineering. His current research interests include matrix converters and ac/dc converters.

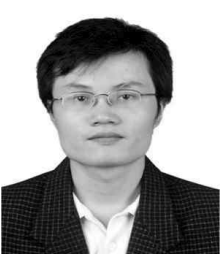

Yao Sun was born in Hunan, China, in 1981. He received his B.S., M.S. and Ph.D. degrees from the School of Information Science and Engineering, Central South University, Changsha, China, in 2004, 2007 and 2010, respectively. He has been an Associate Professor with the School of Information Science and Engineering, Central South University. His current research interests include matrix converters, micro-grids and wind energy conversion systems.

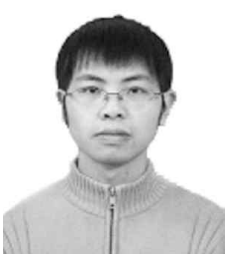

Hui Wang was born in Hunan, China, in 1984. He received his B.S. and M.S. degrees from the Central South University, Changsha, China, in 2008 and 2011, respectively, where he is presently pursuing his Ph.D. degree. His current research interests include indirect matrix converters and $\mathrm{DC} / \mathrm{DC}$ converters.

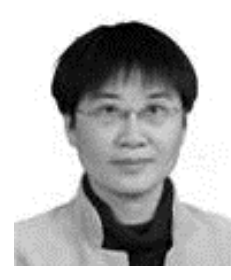

Mei Su was born in Hunan, China, 1967. She received her B.S., M.S. and Ph.D. degrees from the School of Information Science and Engineering, Central South University, Changsha, China, in 1989, 1992 and 2005, respectively. Since 2006, she has been a Professor with School of Information Science and Engineering, Central South University. Her current research interests include matrix converters and wind energy conversion systems. 